\title{
Noise Levels Produced by Agricultural Machinery and Different Farming Processes
}

\author{
Dimitrios Karamousantas, Theodoros Varzakas and Andreas Kanakis \\ Higher Technological Educational Institute of Kalamata, School of Agriculture Technology, Antikalamos, 24100 \\ Kalamata, Greece.
}

\author{
Basile C. Dalamagas \\ Hellenic Environmental Inspectorate, Southern Greece Section, Hellenic Ministry for the Environment Pfysical \\ Planning \& Public Works, 1-3 Kifisias Av., 11523 Athens, Greece
}

(Received 4 June 2009; accepted 15 September 2009)

\begin{abstract}
A characteristic trait of Greek agriculture the last 20 years has been its intense mechanisation. Agricultural machineries are used in almost all phases of daily farming activities in small and large households for a few hours or for as long as 12 or 15 hours. The produced noise usually constitutes danger for the health and the safety of operators. Moreover, it increases the level of environmental noise, particularly in regions of general residence, as well as in tourist regions. Sound-pressure levels produced during the operation of agriculture machineries under different farming processes have been measured. Measurements taken at the height of the operator have been related to European damage-risk criteria, to the requirements of the national legislation for noise protection, and to the maximum environmental permissible noise levels. The result is that permissible noise criteria cannot be met during farming processes. One octave and one-third octave bandwidth measurements have shown the noise content in low-frequency octave band centre frequencies.
\end{abstract}

\section{INTRODUCTION}

In this work, first an effort was made to investigate the acoustic environment from the position of agricultural machine operators, according to Greek and European legislation being in effect. The stimulus for this work occurred when agricultural machine operates complained that their hearing had been differentiated and that they did not hear as well anymore. According them, the high levels of noise produced by the agricultural machineries were responsible. It is a fact that the subject of noise-induced deafness affects all workers in certain sectors of agriculture, industry, and manufacturing. However, workers in rural production, particularly during the months that they harvest, work under a noisy environment for a long time without noise-protection means. High noise levels in conjunction with long work hours could cause temporary or permanent reduction in their hearing. This means that many agricultural machine operators could lose their hearing due to exposure of high noise levels at work, along with all the professional and social consequences.

In Greece, noise in the workplace is described by the Presidential Decree (PD) 149/2006, official government paper, $\mathrm{A} / 159 / 2006,{ }^{1}$ which constitutes harmonisation of the directive 2003/110/EC. ${ }^{2}$ This directive has reformed the limits of noise from an A-weighted sound-pressure level of $90 \mathrm{~dB}(\mathrm{~A})$ to $87 \mathrm{~dB}(\mathrm{~A})$. Occupational hearing loss is considered a professional illness, and sufferers can be awarded $50 \%$ of the rates for disability for noise-induced hearing loss. ${ }^{3}$ Deaf workers must prove that they experienced hearing loss at work.

In this research, noise levels of different tractors have been measured under loaded and unloaded conditions, taking into consideration tractor type, size, and job type. These noise levels have been analysed to find out the increase that takes place under loaded conditions under different one octave and one-third octave band center frequencies. It is shown that low-frequency noise is dominant in the noise-frequency spectrum. This noise is not easily eliminated with traditional, passive hearing-protection devices because low-frequency acoustic waves are long and travel great distances.

Taking into consideration that most farmers report exposure to high noise levels for more than eight hours during farming activities, noise is a real potential danger for the quality of life of agricultural workers. Hearing protectors can decrease the amount of hearing loss caused by noise and, therefore, reduce the amount of communication problems in the everyday lives of farm workers.

Noise annoyance to neighbors due to farming machineries in tourist areas is also a problem. One serious case is noise generated from cannons, which are designed to scare birds and, therefore, must be noisy. Noise produced by harvesters and other agricultural machines will be reported in the future. Additionally, motorbikes cause environmental noise annoyance in tourist areas of Greece, where young persons replace the exhaust system with a noisy one. Previous work by the noise section in the Ministry of Environment has shown that $42 \%$ of the 